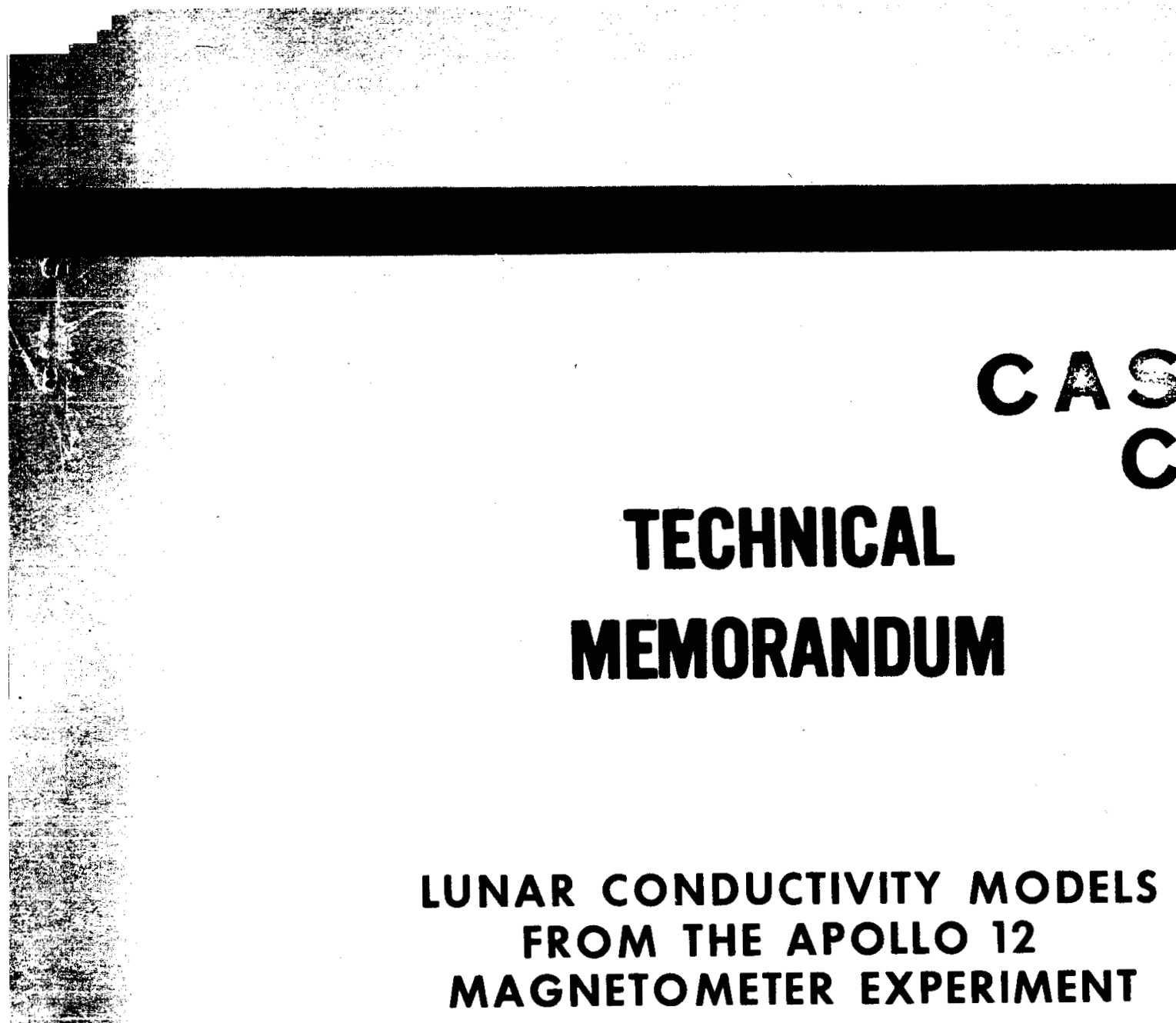

TM-7]

tyotitis

\title{
LUNAR CONDUCTIVITY MODELS \\ FROM THE APOLLO 12 MAGNETOMETER EXPERIMENT
}

\section{Bellcomm}


BELLCOMM, INC.

955 L'ENFANT PLAZA NORTH, S.W., WASHINGTON, D.C. 20024

\section{COVER SHEET FOR TECHNICAL MEMORANDUM}

TITLE- Lunar Conductivity Models from the
Apollo 12 Magnetometer Experiment

FILING CASE NO(S)- 340

\author{
$T M-71-2015-9$ \\ DATE-October 22,1971
}

AUTHOR(S)- W. R. SIIl

FILING SUBJECT(S)

(ASSIGNED BYAUTHOR(S))-

\section{AESTRACT}

A number of conductivity models have been investigated for compatibility with the Apollo 12 magnetometer data. Except at the highest frequencies, a simple core-crust model is compatible with the observed dayside transfer function, which is expressed as the ratio of the lunar surface field spectrum to the interplanetary magnetic field spectrum. All conductivity profiles exhibit a peak near $1500 \mathrm{~km}$, when the models are constrained to conform to the observed flat response at the higher frequencies. However, at frequencies above .01 $\mathrm{Hz}$ the long wavelength limitation of the theoretical model is no longer valid. A combination of dayside and nightside models and data indicate that a conductivity profile with a peak $(.003 \mathrm{mho} / \mathrm{m})$ near $1500 \mathrm{~km}$ radius and a core conductivity of about .01 $\mathrm{mho} / \mathrm{m}$ at $1000 \mathrm{~km}$ is compatible with the observations, as is a monotonic conductivity profile with $.0005 \mathrm{mho} / \mathrm{m}$ at $1600 \mathrm{~km}$ and a core conductivity of $.01 / \mathrm{mho} / \mathrm{m}$ at $1000 \mathrm{~km}$ radius.

A plausible explanation for the difference between the north-south and east-west transfer functions is that it is due to a time varying compression of the remanent (dc) field at the Apollo 12 site by fluctuations in the solar wind plasma. Providing that the spectrum of these compressive fluctuations is not strongly frequency dependent, the result of removing this effect will be to decrease slightly the estimated conductivity. 
COMPLETE MEMORANDUM TO

CORRESPONDENCE FILES:

OFFICIAL FILE COPY

plus one white copy for each

additional cose referenced

TECHNICAL LIBRARY (4)

\section{NASA Headquarters}

R. J. Allenby/MAL

W. O. Armstrong/MTX

P. E. Culbertson $/ M T$

R. J. Green/MAL

E. W. Hall/MTG

R. L. Lohman/MF

A. S. Lyman/MR

M. A. Mítz/SL

W. T. O'Bryant/MAL

R. A. Petrone/MA

A. W. Schardt/SG

A. D. Schnyer/MTE

J. W. Wild/MTE

NASA HQS Library/USS-10

Ames Research Center

D. S. Colburn/SSE

P. Dyal/SSE

D. E. Gault/SSP

W. I. Linlor/SSE

L. Roberts $/ M$

C. P. Sonett/SS

J. R. Spreiter/SST

\section{Goddard Space Flight Center}

J. E. Ainsworth/621

S. J. Bauer $/ 615$

R. E. Hartle/514

J. P. Heppner $/ 612$

G. D. Mead $/ 641$

N. F. Ness $/ 512$

J. A. O'Keefe/640

C. C. Stephanides $/ 620$

D. A. Stern/641

R. G. Stone $/ 615$

W. F. Templemon $/ 252$

D. J. Williams/611
COMPLETE MEMORANDUM TO

Jet Propulsion Laboratory

D. R. Clay/183-401

M. Neugebauer/183-401

R. Phillips/183-501

D. Rea/183-401

E. J. Smith/183-401

C. W. Snyder/183-401

Manned Spacecraft Center

A. W. England/CB

C. R. Nicks/FA4

D. W. Strangway

American Nucleonics Corporation

K. Schwartz

Australian National University

E. Essene

A. E. Ringwood

California Institute of Technology

D. Anderson

L. Davis, Jr.

B. C. Murray

E. Shoemaker

Cornell University

T. Gold

C. Sagan

Environmental Science Service Administration/Boulder

W. N. Hess

J. R. Wait

General Dynamics/Astronautics

J. J. Gilvarry

Geological Survey of Canada

A. Larochelle

E. J. Schwartz 


\section{DISTRIBUTION LIST (Cont'd.)}

Complete Memorandum to

Grant Institute of Geology

G. M. Biggar

M. J. O'Hara

S. W. Richardson

Harvard University

C. Frondel

Lamont-Doherty Geological observatory

M. Ewing

G. V. Latham

Max-Planck Institut für

Extraterrestrische Physik

J. V. Hollweg

Massachusetts Institute of Technology

J. H. Binsack

H. S. Bridge

E. F. Lyon

T. R. Madden

F. Press

M. G. Simmons

G. S. Siscoe

N. Toksoz

National Radio Astronomy observatory

J. W. Findlay

Princeton University

R. A. Phinney
Complete Memorandum to

$\underline{\text { Rice University }}$

A. J. Dessler

J. W. Freeman

F. C. Michael

Royal Institute of Technology/ Stockholm

H. Alfúen

Stanford University

J. R. Booker

J. Clarebout

R. Kovach

The University, Newcastle-upon-Tyne, England

S. K. Runcorn

TRW Systems, Inc.

F. Scarf

University of Virginia

S. F. Singer

U.S. Geological Survey/Flagstaff

R. E. Eggleton

H. Masursky

R. Reagan

D. S. Roddy

U.S. Geological Survey/Menlo Park

R. R. Doell

University of Alaska

S. I. Akasofu 
Complete Memorandum to

University of Arizona

G. P. Kuiper

G. Sil1

University of California at Berkeley

K. A. Anderson

F. S. Mozer

S. Ward

J. Wilcox

University of California at Los Angeles

P. J. Coleman, Jr.

W. M. Kaula

W. W. Rubey

G. Schubert

G. Wetherill

University of California at San Diego

J. Arnold

H. Urey

University of California at Santa Barbara

P. E. Cloud

G. J. F. MacDonald

University of Colorado

E. E. Larson

University of Iowa

J. A. Van Allen
Complete Memorandum to

University of Kansas

D. B. Beard

W. W. Shen

University of Massachusetts

D. U. Wise

University of New Hampshire

L. J. Cahill

University of Sidney

B. O'Brian

University of Texas at Dallas

C. E. Helsley

F. S. Johnson

J. E. Midgley

Bellcomm, Inc.

R. A. Bass

A. P. Boysen, Jr.

J. O. Cappellari, Jr.

F. El-Baz

D. R. Hagner

W. G. Heffron

J. J. Hibbert

N. W. Hinners

T. B. Hoekstra

M. Liwshitz

J. L. Marshall

K. E. Martersteck

J. Z. Menard

G. T. Orrok

P. E. Reynolds

P. F. Sennewald 


\section{DISTRIBUTION LIST (Cont'd.)}

Complete Memorandum to

Bellcomm, Inc. (Cont'd.)

R. V. Sperry

J. W. Timko

A. R. Vernon

R. L. Wagner

Al1 Members, Department 2015

Central Files

Department 1024 File

Library

Abstract Only to

Bellcomm, Inc.

J. P. Downs

I. M. Ross

M. P. Wilson 


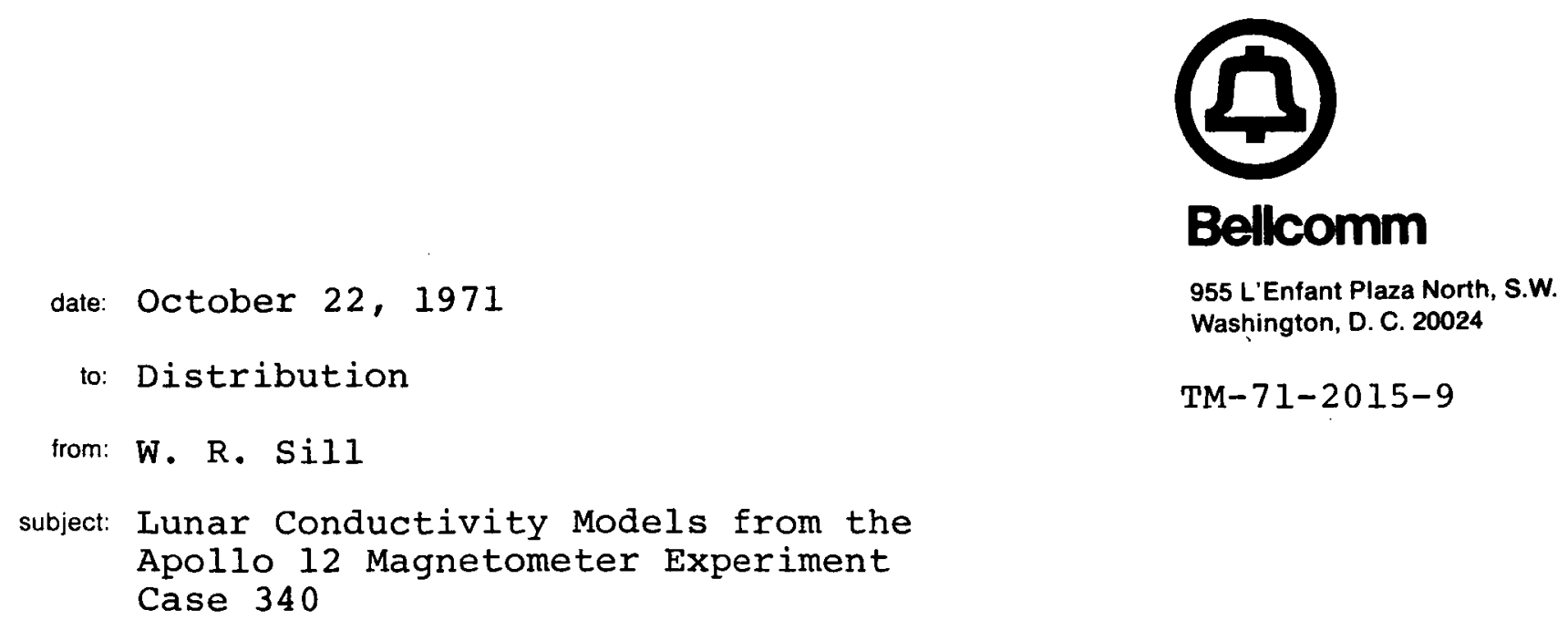

TECHNICAL MEMORANDUM

INTRODUCTION

The Apollo 12 Lunar Surface Magnetometer Experiment has produced some unexpected results, such as the observation of a large remanent (dc) magnetic field, an inductive response to time fluctuations in the interplanetary magnetic field that is a function of the polarization of the fluctuations, and apparent peaks in the observed response (transfer function) to the time fluctuations [Dyal and Parkin, 1971; sonett et al., $1971 \mathrm{a}, 1971 \mathrm{~b}]$. On the interpretational side, the rapid rise and then leveling off of the transfer function, as determined from the lunar dayside data, has been taken as indicating a thin, highly conducting shell at a depth of about $250 \mathrm{~km}$ [Sonett et al., $1971 \mathrm{a}, 1971 \mathrm{~b}$ ], while the nightside data has been interpreted in terms of a monotonically increasing conductivity structure. In this paper $I$ intend to pursue some of the implications of these observations and determine their effects on the interpretation of the data in terms of the conductivity models.

Theoretical Model

Figure 1 shows the geometry on the dayside lunar equator and in this coordinate system the field components due to the interplanetary field and the induced fields are [Sill and Blank, 1970]

$$
\begin{aligned}
& B_{x}=B_{o x} \\
& B_{y}=H_{p} B_{o y}-H_{t}\left(V_{x} *_{o y}\right)+H_{t}\left(V_{y}{ }^{*} B_{o x}\right) \\
& B_{z}=H_{p} B_{o z}-H_{t}\left(V_{x}{ }^{*} B_{o z}\right)
\end{aligned}
$$


where all quantities are to be considered as functions of frequency, $H_{p}$ and $H_{t}$ are the Poloidal and Toroidal transfer functions, respectively, and the solar wind components are (neglecting aberation and fluctuations out of the ecliptic)

$$
\begin{aligned}
& v_{x}=-v_{\text {sw }} \cos \phi \\
& v_{y}=v_{\text {sw }} \sin \phi
\end{aligned}
$$

The constraints imposed in the above derivation are [Blank and Sill, 1969; Sill and Blank, 1970], (1) the wavelength of the source field fluctuation is much greater than the radius of the moon, which, for spatial irregularities convected with the solar wind, requires that the frequency of the associated time variations be much less than $0.1 \mathrm{~Hz}$, (2) the lunar conductivity profile is radially symmetric, (3) a thin current sheet at the lunar surface confines the induced fields to the lunar interior, (4) the day-night asymetry in the solar wind plasma interaction with the moon, which results in the plasma void behind the moon, produces small effects on the induced fields on the sunlit hemisphere.

Model studies indicate that $\mathrm{H}_{\mathrm{p}}$ is an increasing function of frequency in the frequency range where induction occurs in the more conductive portions of the lunar interior, while $\mathrm{H}_{t}$ is independent of frequency until induction occurs in the least conductive regions near the lunar surface, at which point $\mathrm{H}_{t}$ decreases with frequency [Sill and Blank, 1970].

Discussion of the Observations

$$
\left(A_{i}=\left|B_{i}\right| /\left|B_{o i}\right|\right), i=x, y, z, \text { (average of } 14 \text { spectra }
$$

representing 21 hours of data) as determined from measurements made on the lunar surface by the Apollo 12 magnetometer and in the solar wind by Explorer 35 [Sonett et al., $1971 \mathrm{~b}$ ]. The observed vertical transfer function $\left(A_{x}\right)$ is near unity in accord with (1), but it shows a tendency to decrease at the higher frequencies, perhaps indicating that the approximation of an infinitely thin confining current sheet is no longer valid. The observed horizontal transfer functions $\left(A_{y}, A_{z}\right.$ ) increase with frequency indicating a dominant contribution from the poloidal response. However, $A_{z}$ is consistently 
larger than $A_{y}$ and this has been suggested as an indication of a contribution from the toroidal response [Sonett et al., $1971 \mathrm{a}, 1971 \mathrm{~b}]$. From equations 2 and 3 , assuming that $\mathrm{v}_{\mathrm{x}^{\prime}}$ $\mathrm{V}_{\mathrm{y}}$ have a dc component only and that $\mathrm{H}_{t}$ is real, the ratios of the power spectra are,

$$
\begin{aligned}
A_{z}^{2}= & \left|H_{p}\right|^{2}-2 V_{x} H_{t} \operatorname{Real}\left[H_{p}\right]+\left(V_{x} H_{t}\right)^{2} \\
A_{y}^{2}= & A_{z}^{2}+\left(V_{y} H_{t}\right)^{2}+2 V_{y} H_{t} \operatorname{Real}\left[\left(H_{p}-V_{x} H_{t}\right)\right. \\
& \left.B_{O x}^{*} B_{O y} / B_{O y} B_{O y}^{*}\right]
\end{aligned}
$$

Therefore $A_{z}>A_{y}$, if the sum of the last two terms in (7) is negative. Since $\mathrm{H}_{t^{\prime}} \mathrm{H}_{\mathrm{p}}$ and $-\mathrm{V}_{\mathrm{x}}$ are positive, a necessary condition is that the product $V_{y}$ Real [ $B^{*}{ }_{o x} B_{o y}$ ] be negative. From (5) and Figure 1 we see that $V_{y}$ is negative before local noon and positive after local noon. Observations of the $x$ and $y$ components of the interplanetary magnetic field show both positive and negative correlations, e.g., Figures $14 \mathrm{a}, 14 \mathrm{~b}$ of Dyal et al., [1970]. Therefore, if we require $A_{z}>A_{y}$ by the above mechanism, those spectra averaged in Figure 2 which represent measurements made before local noon $\left(V_{Y}<0\right)$ must be dominated by positively correlated events in the cross-spectrum (Real $\left[\mathrm{B}_{\mathrm{Ox}}^{*} \mathrm{~B}_{\mathrm{OY}}\right]>0$ ) and those which represent measurements made after noon $\left(V_{Y}>0\right)$ by negatively correlated events. These requirements seem like a rather restrictive set of conditions.

The last condition, that the magnitude of the last term in (7) be greater than the second, poses no serious problem; if the poloidal response is greater than the toroidal response and if the spectral ratio term is not too small. For $\mathrm{H}_{\mathrm{p}}$ in the range from 1 to 3 , and ( $\mathrm{B}_{\mathrm{Ox}}^{*} \mathrm{~B}_{\mathrm{Oy}} / \mathrm{B}_{\mathrm{oy}} \mathrm{B}_{\mathrm{oy}}^{*}$ ) about $1 / 2$, values for $\mathrm{V}_{\mathrm{y}} \mathrm{H}_{\mathrm{t}}$ in the range from $1 / 2$ to 2 are compatible with the observed differences between $A_{z}$ and $A_{y}$. A test for the contribution from the toroidal interaction can be made by the analysis of data collected at local noon, for then $A_{z}$ should equal $A_{y}$. 
Alternatively, if the toroidal response is negligible, then the difference between the horizontal transfer functions could be attributed to a more complicated conductivity structure including variations in latitude and longitude, or to other asymmetric aspects of the interaction such as the day-night asymmetry.

Another possibility is a contribution to the lunar surface spectra from a variable compression of the local remanent (dc) field. The remanent field should interact with the incoming solar wind plasma in a fashion similar to that of the induced fields [Blank and Sill, 1969]: The gist of this interaction is that the deflection of the particles by the magnetic field gives rise to a current which excludes the field from the bulk of the plasma and confines it to a region near the lunar surface. The thickness of the current sheath is of the order of $\mathrm{c} / \mathrm{\omega}_{\mathrm{p}}$ or about 5 to $10 \mathrm{~km}$. Perturbations in the solar wind plasma parameters should then cause fluctuations in the interaction current and thereby give rise to a fluctuating magnetic field which is proportional to the remanent field.

Dyal and Parkin [1971] observed fluctuations in the 3 hour averages of the field components that are proportional to the remanent field and the energy density of the solar wind. They suggest that these are due to the compression of the remanent field by the solar wind. Assuming a mechanism of this type and neglecting the toroidal interaction, the field at the lunar surface would be

$$
\begin{aligned}
& B_{y}=H_{p} B_{o y}+K B(d c)_{y} \\
& B_{z}=H_{p} B_{o z}+K B(d c)_{z}
\end{aligned}
$$

where $\mathrm{K}$ is the spectrum of the compression factor, which is a function of the solar wind parameters, and $B(d c)_{Y}=13 \gamma$, $B(d c)_{z}=25.6 \gamma$ are the horizontal components of the remanent field at the Apollo 12 site. Since the remanent $z$ component is about twice as large as the $y$ component, this mechanism will contribute proportionately more power to the $z$ spectra, thereby providing an explanation for the observation that $A_{z}$ is greater than $A_{y}$. In order for the remanent field fluctuations to be effective, their amplitude should be of the same order as the inductive fluctuations or about several gammas. 
Fluctuations of this order are observed in the three hour averages of the difference between the lunar surface field and the interplanetary magnetic field [Dyal and Parkin, 1971]. For the case where the confining current layer thickness, remanent field scale size and distance from the source are all of the same order $(10 \mathrm{~km})$, a ten percent fluctuation in the solar wind plasma density will give rise to a fluctuation of similar magnitude in the confined remanent field or a fluctuation of several gammas. Therefore, such a mechanism would appear quite plausible.

Inspection of the individual spectra, as measured in the solar wind and on the lunar surface, [Sonett et al., $1971 \mathrm{~b}]$ indicates that for the surface fields $\left|\mathrm{B}_{\mathrm{z}}\right|^{2}>\left|\mathrm{B}_{\mathrm{Y}}\right|^{2}$ over the whole Erequency range, while in the solar wind $\left|\mathrm{B}_{\mathrm{Oz}}\right|^{2}<\left|\mathrm{B}_{\mathrm{OY}}\right|^{2}$ for $\mathrm{f}<10^{-2} \mathrm{~Hz}$ and $\left|\mathrm{B}_{\mathrm{Oz}}\right|^{2} \approx\left|\mathrm{B}_{\mathrm{OY}}\right|^{2}$ for $\mathrm{f}>10^{-2} \mathrm{~Hz}$. Therefore, the relative contribution from fluctuating compression is greater at the lower frequencies. In any case, $A_{y}$ is less contaminated by these effects simply because the $Y$ component of the remanent field is less than the $z$ component.

Finally, some explanation must be offered for the apparent peaks in the observed transfer functions as they are not consistent with the proposed theoretical model. One possible explanation is that they are the result of the excitation of higher order modes by the shorter wavelengths of the high frequencies. As was pointed out previously, the approximation of a uniform source field limits the application of the theoretical model to frequencies much less than $0.1 \mathrm{~Hz}$. For the convection of spatial fluctuations in the interplanetary field, the phase difference across the moon is as least $15^{\circ}$ at $10^{-2} \mathrm{~Hz}$ and it increases to at least $45^{\circ}$ at $3 \times 10^{-2} \mathrm{~Hz}$. Certainly the approximation of a uniform source field is not applicable at these high frequencies. On the other hand, there is no evidence that the excitation of higher order modes will lead to a peaked response. Consideration of a "resonant" cavity effect leads to improbably large length scales or extremely low electromagnetic wave velocities.

With respect to these peaks in the observed transfer function, it is important to note that the individual spectra, in the solar wind as well as on the lunar surface, exhibit peaks near and above $10^{-2} \mathrm{~Hz}$ [Sonett et al., $1971 \mathrm{~b}$ ] and that there is even a suggestion that the peaks are harmonically related. Peaks in the spectra of the interplanetary magnetic field at these frequencies have also been observed by earth 
orbiting spacecraft [Fairfield, 1969; Scarf et al., 1970] The fluctuations responsible for these peaks are observed upstream from the earth's bowshock when the field line from the spacecraft intersects the shock. It has been proposed that these fluctuations are waves generated through a plasma instability by high velocity protons traveling upstream from the shock. Correlations between the magnetic field fluctuations and suprathermal protons as well as other solar wind parameters have been observed [Scarf et al., 1970].

Such fluctuations in the solar wind parameters could lead to peaks in the lunar surface spectrum, through a variable compression of the remanent field, if the spectrum of the compression factor in (8) and (9) is peaked. Peaks in the spectrum of the solar wind velocity at frequencies near $10^{-2} \mathrm{~Hz}$ have been reported [Coleman, 1966]. As noted previously, modest changes in the solar wind parameters ( $10 \%$ ) could lead to compressional fluctuations of a few gammas.

A priori, it is also possible that the toroidal interaction, which is dependent on the convolution of $B_{0}(\omega)$ and $\mathrm{V}_{\mathrm{sw}}(\omega)$, could contribute to the peaks in the spectra. In this case the convolution of the spectra would give rise to peaks at the sum and difference frequencies for fluctuations in $B_{0}$ and $V_{s w}$ which are correlated. Thus, this mechanism is capable of introducing additional power into different portions of the surface spectra and this characteristic could be used as a diagnostic feature of this interaction. Measurements of the solar wind spectrum [Coleman, 1968] show that typical fluctuations in the frequency range from $10^{-3}$ to $10^{-2}$ are of the order of $10 \mathrm{~km} / \mathrm{sec}$. Since the toroidal contribution from the steady (dc) component of the wind is at least an order of magnitude greater than the fluctuations at these frequencies, it seems less likely that the above mechanism could produce an important effect.

Conductivity Models

With the above discussion of the data and the theoretical model in mind, let us examine several conductivity models which purport to fit the observed transfer function. Figure 3 shows a comparison of three poloidal response models to the observed RMS transfer function, $\langle A\rangle=\left[.5\left(A_{y}^{2}+A_{z}^{2}\right)\right]^{l / 2}$. The simple core-crust model provides an adequate fit to the data except at the highest frequencies where the response is still increasing with frequency, while the observed response has flattened out. 
As has been mentioned several times previously, this high frequency region is where the assumption of a uniform source field breaks down and perhaps because of this (and the peaks), we should use caution in constraining the models to fit the data in this region, at least until we have a better understanding of the nature of the interaction in this frequency range. Sonett et al., [1971 b] attempted to fit a core-crust model (core radius $=1560 \mathrm{~km}$, core conductivity $=7.4 \times 10^{-4} \mathrm{mho} / \mathrm{m}$ ) to the data, but the calculated response did not show very good agreement. Apparently, some of the problem is attributable to a computation technique which leads to an overestimate of the high frequency response. This effect can also be seen by comparing models 3 and Sonett's best fit model (1) in Figure 3. Here we note that the response of model 3, even with its slightly higher conductivity exterior to the peak, is lower and flatter than Sonett's model at the higher frequencies.

In Figure 4, models 4 and 5 show some of the effects of changing the conductivity profile near the peak. Model 4 has a broader and less conductive shell near $1500 \mathrm{~km}$ as compared to model 3. The response of model 4, compared to 3, is slightly greater at frequencies above $10^{-2} \mathrm{~Hz}$, which is partly attributable to the higher conductivity in the region between $1525 \mathrm{~km}$ and $1550 \mathrm{~km}$. This is partly in contradiction of the statement in Sonett et al., [1971 b], that a better fit of the model at the higher frequencies will probably lead to both a higher value of the maximum conductivity and a steeper slope of the conductivity profile at the outer edge. Model 5 shows that the transfer function is not very sensitive to the structure just below the peak; here the increase in the conductivity between $1200 \mathrm{~km}$ and $1450 \mathrm{~km}$ is compensated by a slight thinning of the highly conducting shell. Figure 5 pursues this effect. In these models the thinning of the shell is compensated by an increase in the shell and core conductivity.

These models illustrate something of the permissible range of models that will fit the data. If we require the response to be flat at the higher frequencies, all the models exhibit a peak in the conductivity near $1500 \mathrm{~km}$. However, there is some spread in the models and the conductivity profile just below the peak is not strongly limited. If we relax the constraint on the flatness of the high frequency response, a simple core-crust model will fit the low frequency data.

So far the models have been fit to the observed RMS transfer function, but in the previous discussion of why $A_{z}>A_{y}$, two of the mechanisms (toroidal interaction and compression of $B(d c)$ ) were based on effects which would channel 
more extraneous power into the $\mathrm{z}$ component spectra at the lunar surface. In both these cases the $A_{y}$ transfer function should be closer to the pure poloidal transfer function. Figure 6 is a fit of a model to $A_{y}$ and $A_{z}-.4$ where .4 is the average difference between $A_{z}$ and $A_{y^{*}}$ Model 6 is similar to models 3 and 5 with a slightly thinner and less conductive shell and a less conductive core. The core-crust model 7 is slightly less conductive than that in Figure 3 .

If the difference between $A_{z}$ and $A_{y}$ is due to contamination of the spectra from either a weak toroidal interaction or a variable compression of the remanent field, then the appropriate models will be much like those in Figures 3-6 with slightly greater depths of the layers and slightly reduced conductivities. However, the picture could be altered significantly if the proposed contamination mechanisms are strongly frequency dependent, as seems more likely for the compression of the remanent field. Some of these questions about the mechanism could be answered by a careful examination of the data, especially at low frequencies, and also by measurements that will be made at future Apollo landing sites.

The analysis of the nighttime data, when the magnetometer is exposed to the plasma void behind the moon, has proceeded by matching the observed time domain response to models of the moon represented by a sphere in a vacuum [Dyal et al., 1970, Dyal and Parkin, 1971]. The response of a sphere in a vacuum to a step function change in the source field is characterized by a decay from the initial to the final value for the radial component and by an overshoot and then a decay to the final value for the tangential components. Qualitatively such a response is observed in the nighttime data; however, deviations from the theoretical response of a sphere in a vacuum are observed. Some of these effects are illustrated in Figure 7 [Dyal et al., 1970]. Note that the step change in the tangential field as observed at Explorer 35 results in an overshoot at the lunar surface which is more than twice the magnitude of the source field change. Also, the radial component $(x)$ at Explorer 35 shows no pronounced low frequency change at the time of the step change in the tangential components, but at the lunar surface there is a large transient in the radial component.

A model consisting of a sphere with confining currents distributed along a tangential cylinder, representing the boundary of the plasma void, would probably be a more appropriate model for the nighttime response. Such a model would account for the amplification greater than 1.5 and the crosstalk between components by the compression and distortion of the induced dipole-like field. 
The absence of the diamagnetic solar wind plasma on the night side could also contribute to an observed amplification greater than 1.5. In this case, suppose that the source field in the void is about $30 \%$ greater than in the solar wind because of the plasma diamagnetism, the initial overshoot could be nearly twice as great as the magnitude of the step as observed in the solar wind. Another effect would be that the decay would asymptotically approach a value some $30 \%$ greater than that seen in the solar wind. Since the field is rarely steady for long enough periods, it is difficult to test this effect. In any case the crosstalk between components and the suggestion that the amplification may be even larger than 2 at the higher frequencies favors partial compression and distortion as a dominant mechanism.

Figure 8 shows the calculated time response of layered sphere models in a vacuum to a simulation of an observed transient [Dyal et al., 1970] in the radial component and Figure 9 shows the frequency domain response. In the time domain, the calculated response of the core-crust model suggested by Dyal and Parkin [1971] is larger than the observed response for all times shown. The 3-layer model of Dyal and Parkin [1971] has a highly conductive core and its response is larger than the observed one for the first $200 \mathrm{sec}$, but at longer time it matches the observed surface response. Model 3, after Sonett's conductive shell model, fits the first 200 sec of the observed response rather well, but it is larger than the observed for later times. A model (3c) composed of model 3 with a highly conductive core as in the 3-layer model of Dyal and Parkin seems to give a very good fit to the surface response over the complete time span shown, as does model $2 \mathrm{c}$ which is like the model 2 with the addition of a conductive core. The fact that the calculated response is below the input response at $300 \mathrm{sec}$ indicates that induced currents are still flowing in the conductive interior and Figure 9 shows that these models have the largest response at the low frequencies.

For comparison Figure 10 shows the observed and calculated transients in the $\mathbf{z}$ component which occurred at the same time as the $x$ component transient shown in Figure 8 . Here, none of the models provides an adequate fit to the observation. The obvious discrepancy is that the magnitude of the observed surface response is much greater than the calculated response. The initial value of the observed overshoot $(\sim 14 \gamma)$ is about twice as large as the step change in the solar wind field $(\sim 7 \gamma)$, while the calculated overshoot is about what would be expected from Figures 9 and 10 , ( $i . e .1 .3 \times 7 \gamma \cong 9 \gamma$ ). This discrepancy is probably due to partial confinement effects. 
As a final example Figure 11 shows another observed transient in the radial component and the response of the same five models. During the first $300 \mathrm{sec}$ all the models give a response that is greater than the observed one. The models with the least conductive interiors (core-crust and 3 ) have as expected the largest response at $300 \mathrm{sec}$, however, the decay of the conductive shell model (3) after $300 \mathrm{sec}$ is much slower than the core-crust model. The 3-layer model has a very rapid decay after $300 \mathrm{sec}$ when compared to the core-crust model because the currents induced in the innermost core during the first 300 sec very nearly cancel the current induced by the drop in the field at $300 \mathrm{sec}$. Here, again, the conductive shell model with a highly conductive core (3c) and model $2 \mathrm{c}$ provide a better, but not wholely adequate, fit to the observed response.

$\underline{\text { Summary }}$

For a completely dominant poloidal interaction, a simple core-crust model provides an adequate fit to the observed dayside RMS transfer function except at the highest frequencies. The requirement that the calculated poloidal response match the relatively flat observed response in the high frequency region lepads to models which have a peak in the conductivity profile near $1500 \mathrm{~km}$. However, examination of several models indicates that the conductivity structure below this depth is not strongly limited by the present dayside data. Extension of the frequency domain analysis to lower frequencies will be required to determine the deeper conductivity structure and wiil aid in the clarification of other questions such as the importance of the toroidal interaction.

It seems plausible that the difference between the observed horizontal transfer functions (i.e., $A_{z}>A_{y}$ ) is due to a time variable compression of the remanent field driven by fluctuations of the solar wind plasma. In such a case the amplitude of the fluctuation is proportional to the strength of the remanent field and, therefore, the observed transfer function $A y$ is closer to the true inductive transfer function simply because the magnitude of the $y$ component of the remanent field is smaller than the $z$ component. The models that are fit to the $y$ transfer function are slightly less conductive than those that are fit to the RMS transfer function. Provided that the spectrum of the compressive fluctuations is not a strong function of frequency, we anticipate that the complete removal of the compressive effects will lead to models slightly less conductive than those that have been previously presented. If the compressive fluctuations of the remanent field are strongly frequency dependent, then the resulting models could be significantly different. (Preliminary results from the Apollo 15 
magnetometer indicate a very small remanent field, $<5 \gamma$ [Dyal, 1971, personal communication]. Contamination of the induction field spectra by compression of the remanent field should be minimum at this location.)

During the lunar night the data is less likely to be contaminated by compression of the remanent field because of the absence of the solar wind plasma at the lunar surface. However, the partial confinement of the induction field within the plasma void limits the utility of the sphere-in-a-vacuum model for the nightside response. Within the limitation of this model, it is found that either Sonett's conductive shell model with the addition of a highly conductive core (model 13c) or a monotonic conductivity model (2c) provide the best (but not completely adequate) fit to the nightside radial component transient data. Inclusion of the conductive core in either of these models does not appreciably alter the dayside transfer function above $10^{-3} \mathrm{~Hz}$, so that these models are compatible with the present dayside data as well.

2015-WRS-pjr U. L S Dll

Attachments

W. R. Sill 


\section{(ㄱ)}

REFERENCES

Blank, J. L., and W. R. Sill, Response of the Moon to the time-varying interplanetary magnetic field, J. Geophys. Res., 74, 736, 1969 .

Coleman, P. J., Jr., Variations in the interplanetary magnetic field: Mariner 2, J. Geophys. Res., 71, 5509, 1966.

Coleman, P. J., Jr., Turbulence, viscosity and dissipation in the solar wind plasma, Astrophys. J., 153, 371, 1968.

Dyal, P., C. W. Parkin, C. P. Sonett, and D. S. Colburn, Electrical conductivity and temperature of the lunar interior from magnetic transient measurements, NASA TM

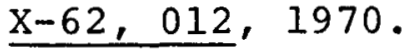

Dyal, P., and C. W. Parkin, The Apollo 12 magnetometer experiment: Internal lunar properties from transient and steady magnetic field measurements, Proceedings of the Apollo 12 Lunar Science Conference, (in press) The M.I.T. Press, 1971.

Fairfield, D. H., Bow shock associated waves observed in the far upstream interplanetary medium, J. Geophys. Res., 74, $3541,1969$.

Scarf, F. L., R. W. Fredricks, L. A. Frank, C. T. Russel, P. J. Coleman, Jr., and M. Neugebauer, Direct correlations of large amplitude waves with suprathermal protons in the upstream solar wind, J. Geophys. Res., 75, 7316, 1970.

Sill, W. R., and J. L. Blank, Method for estimating the electrical conductivity of the lunar interior, J. Geophys. Res., 75, 201, 1970 .

Sonnett, C. P., D. S. Colburn, P. Dyal, B. F. Smith, G. Schubert, and K. Schwartz, Lunar electrical conductivity profile, Nature, 230, 359, 1971 a.

Sonett, C. P., G. Schubert, B. F. Smith, K. Schwartz, and D. S. Colburn, Lunar electrical conductivity from Apollo 12 magnetometer measurements: Compositional and thermal inferences, proceedings of the Apollo 12 Lunar Science Conference, (in press) The M.I.T. Press, 1971b. 


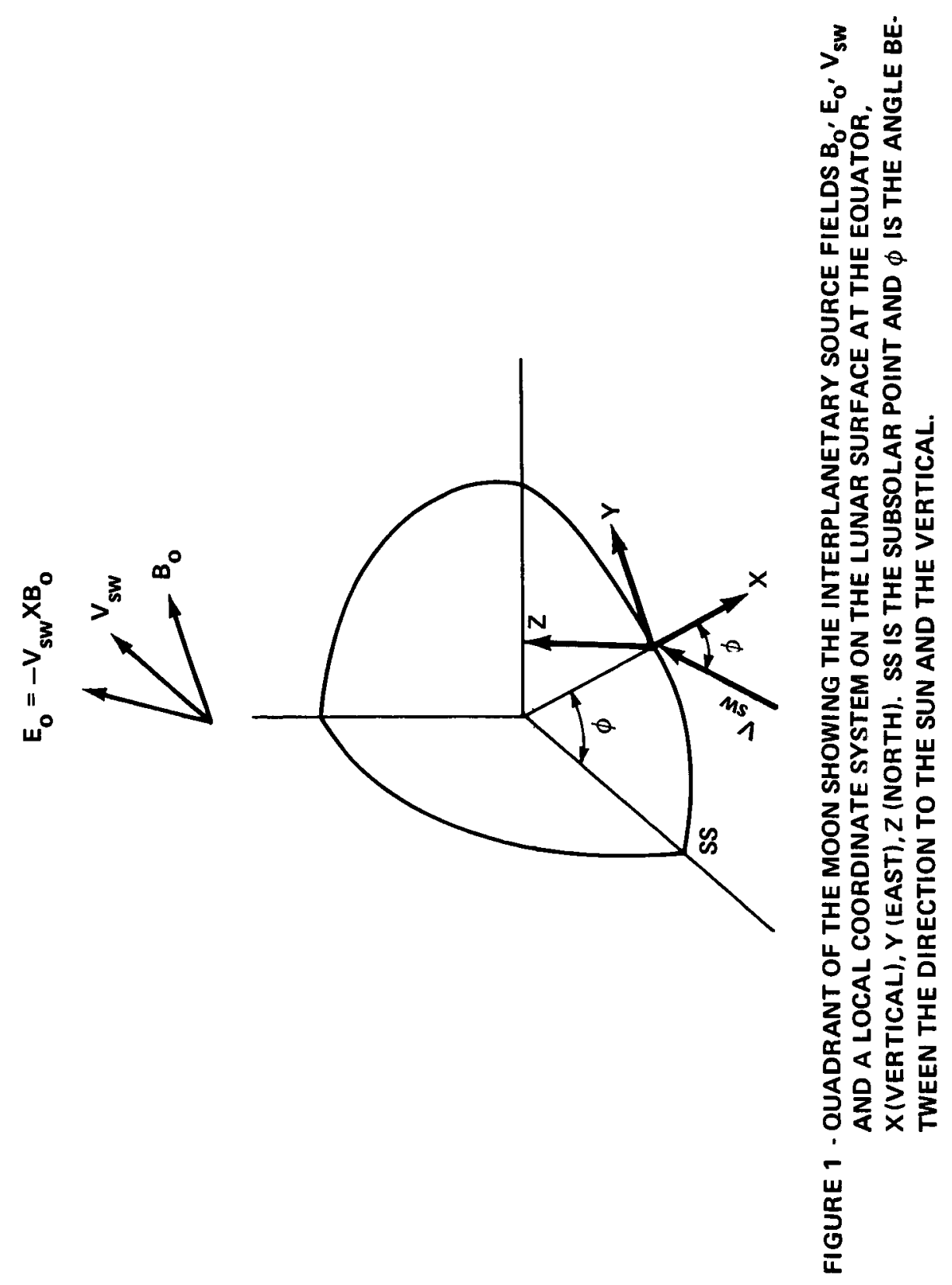




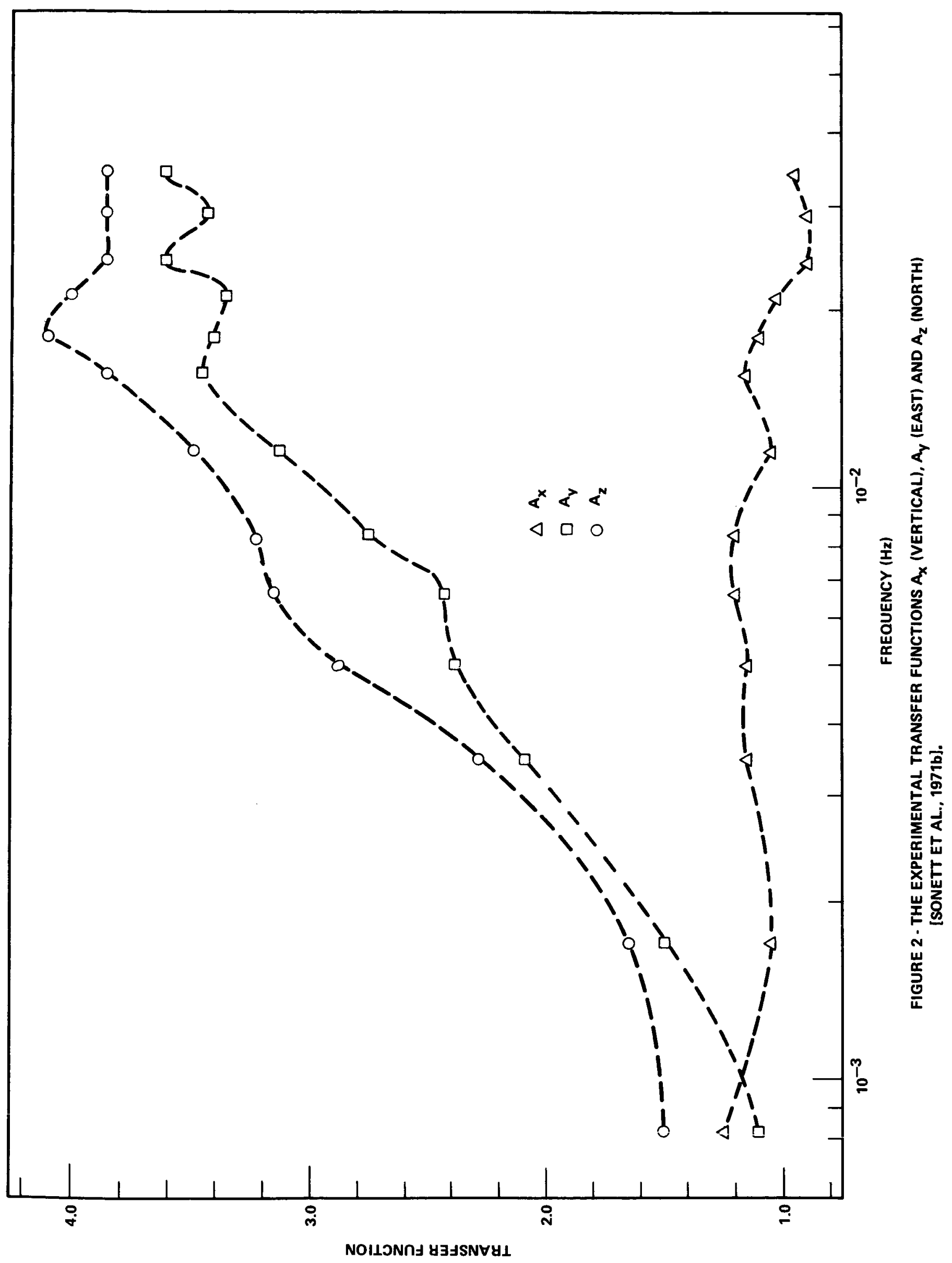




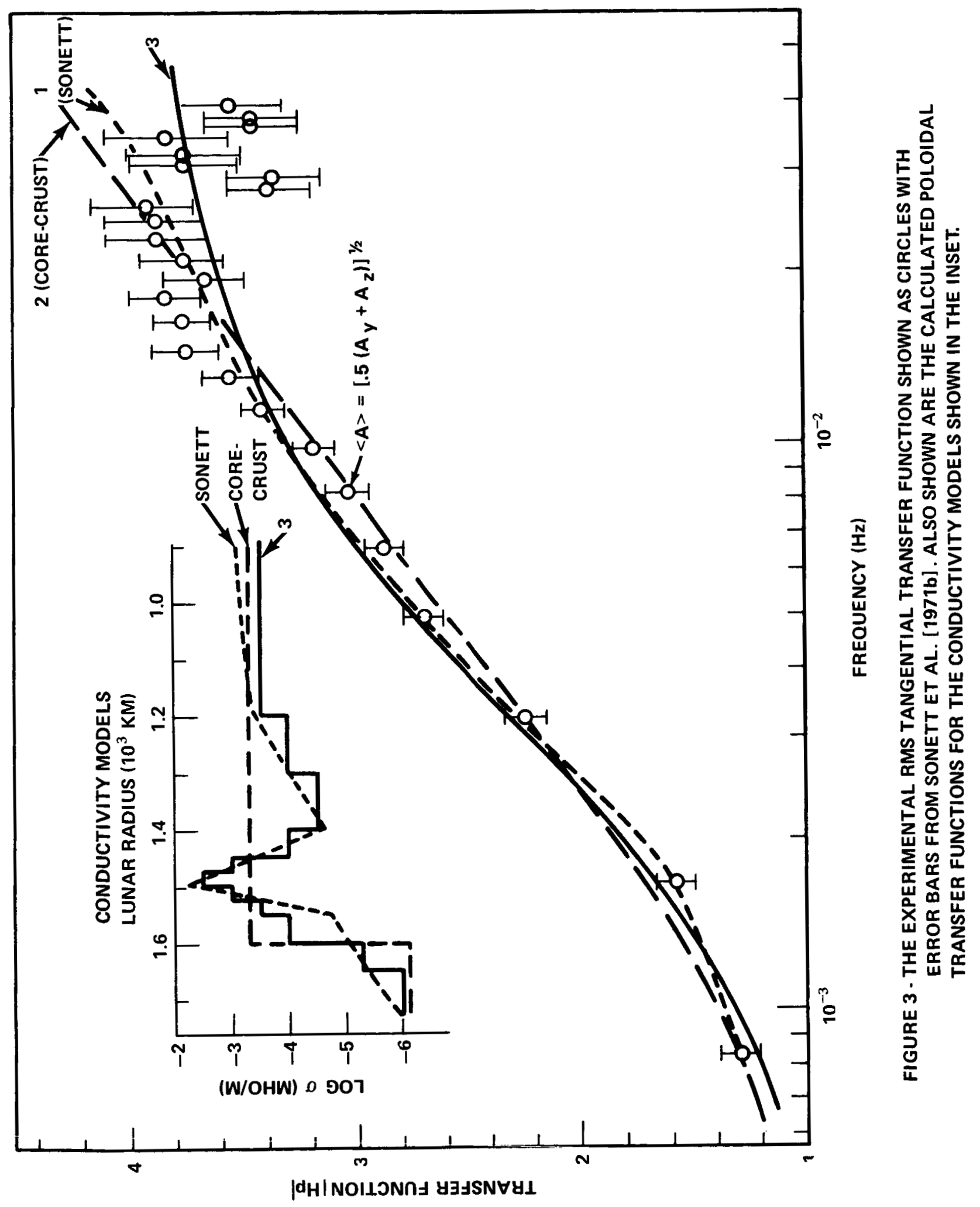




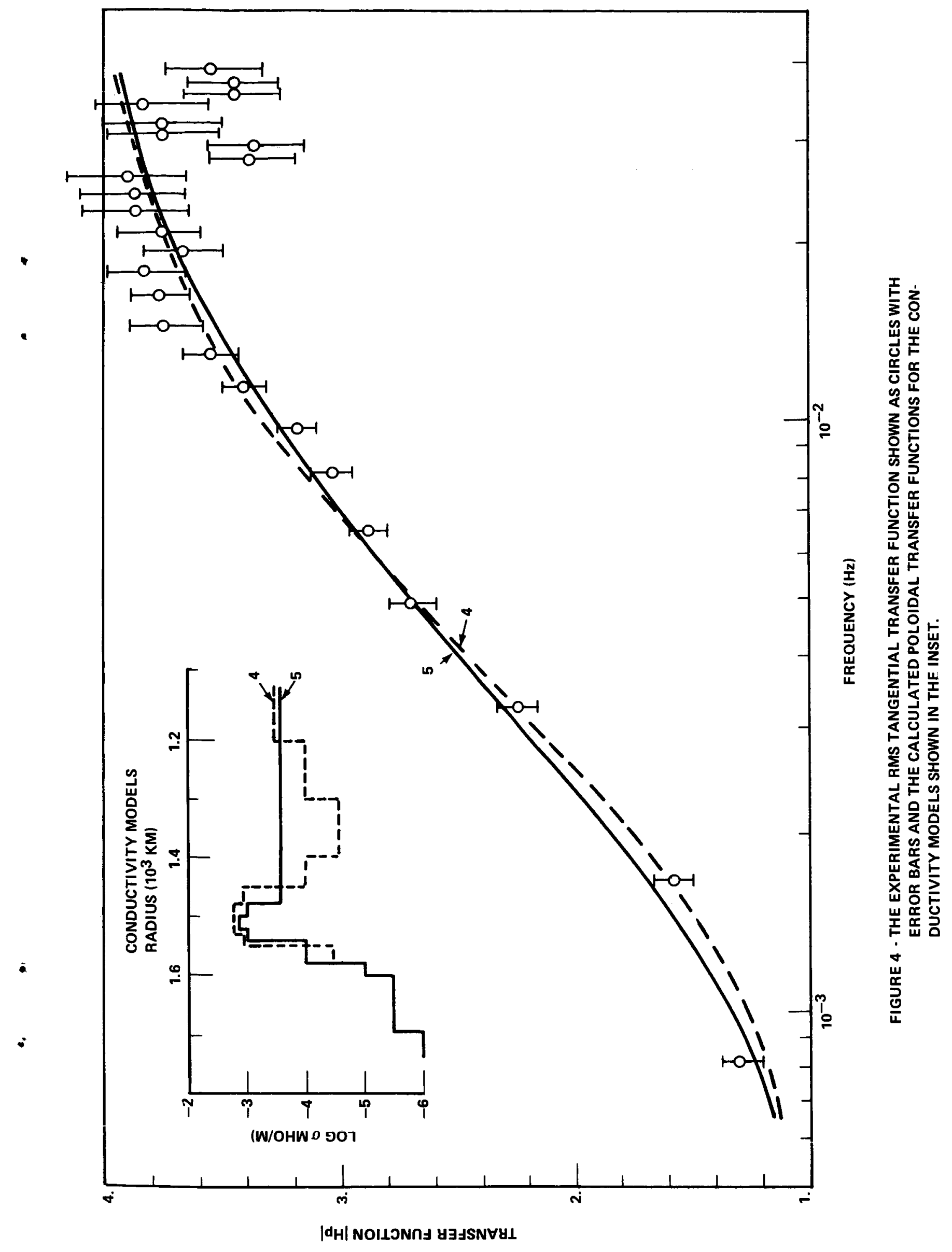




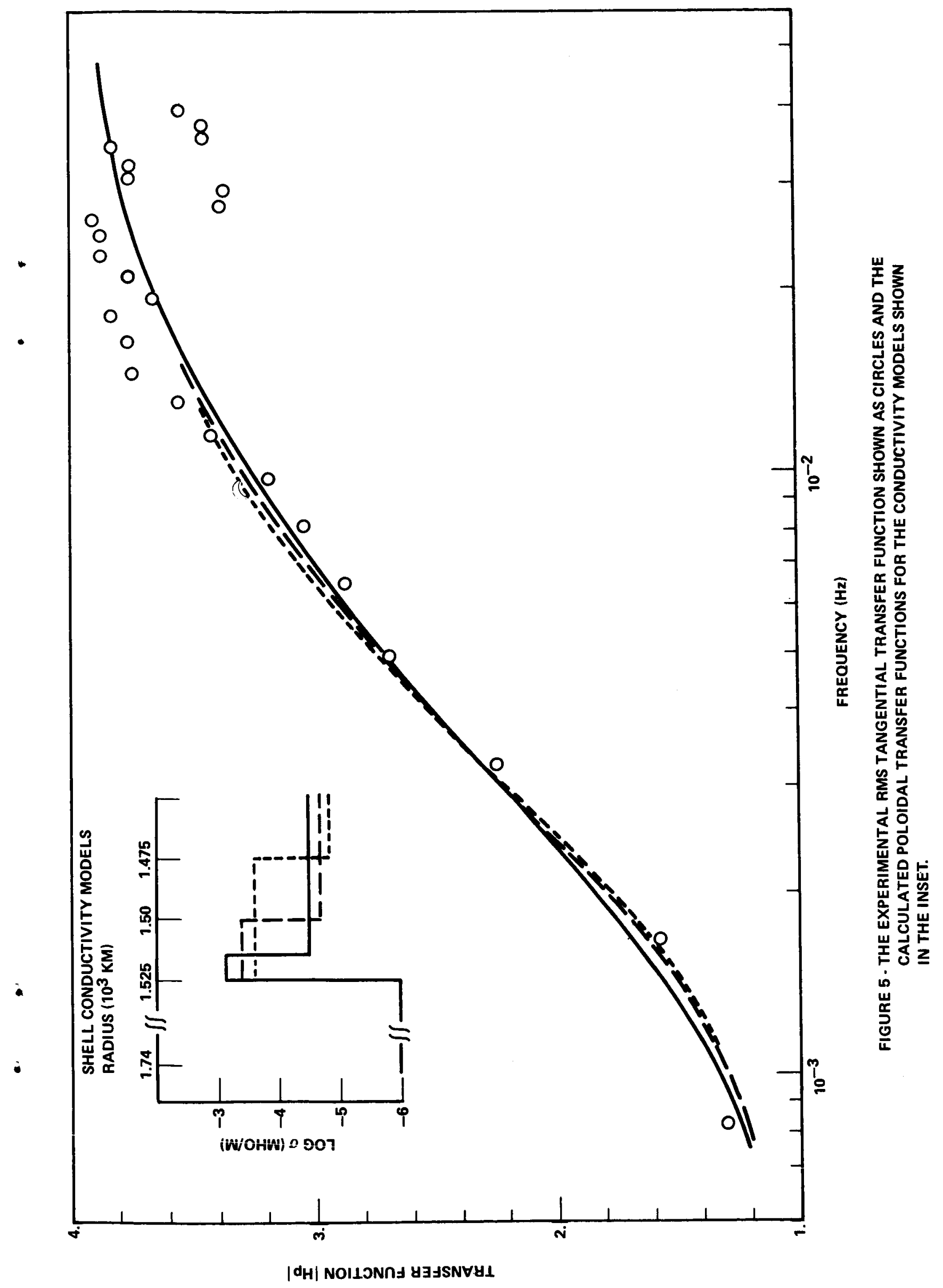




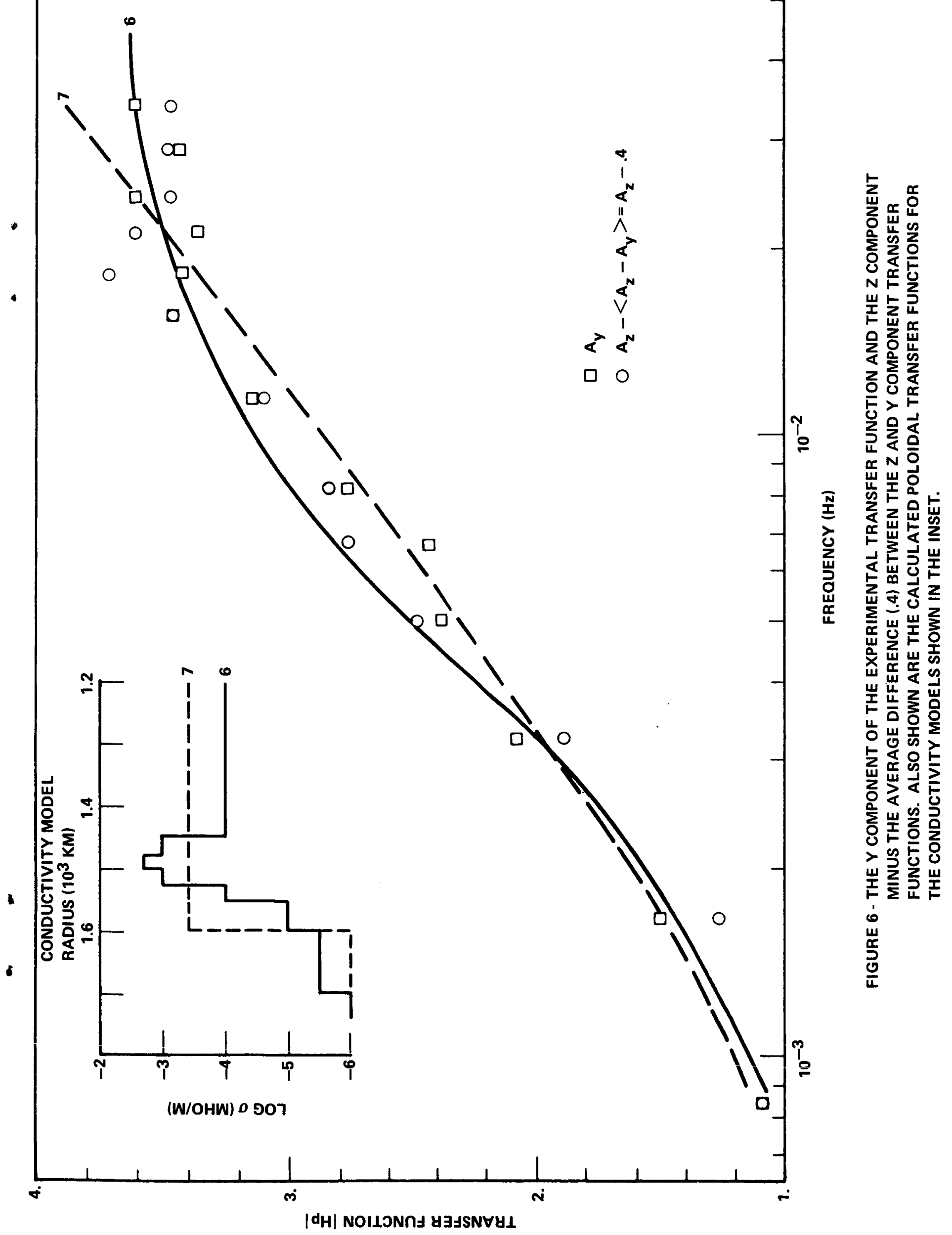




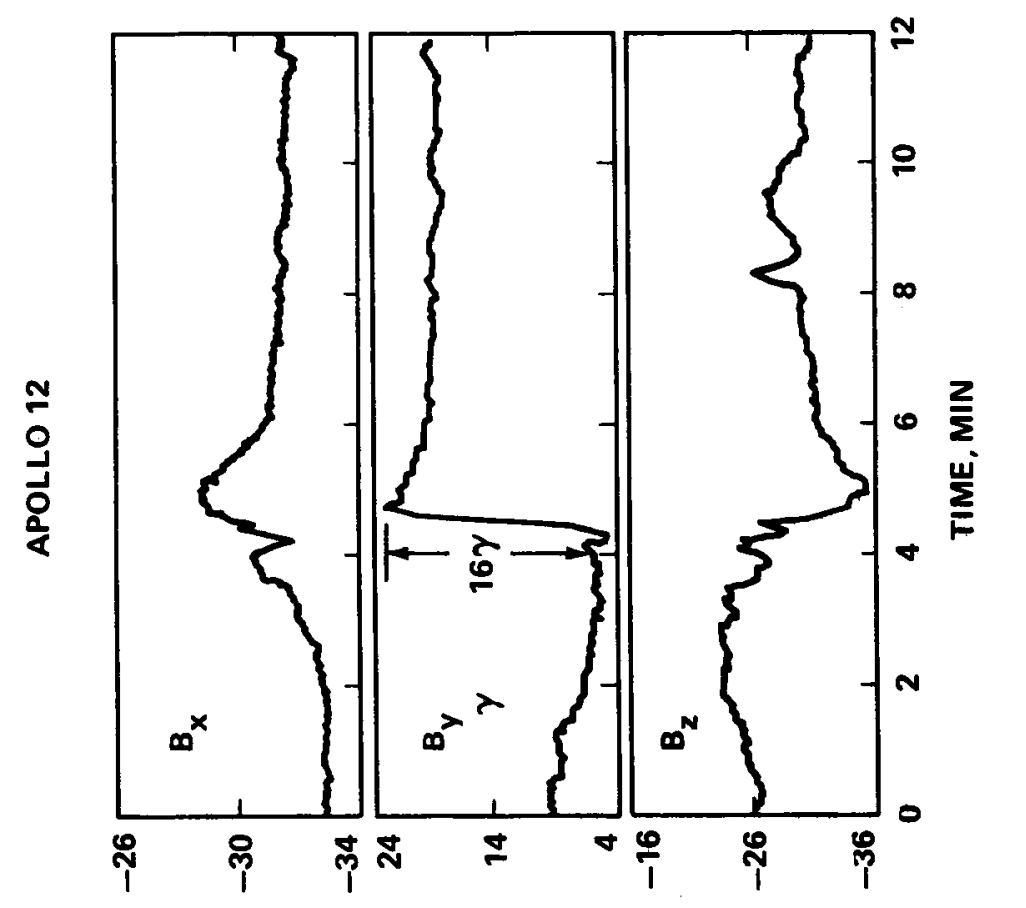

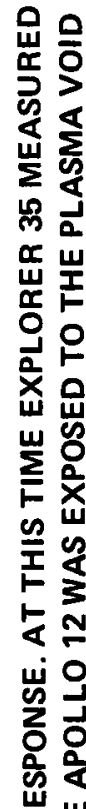

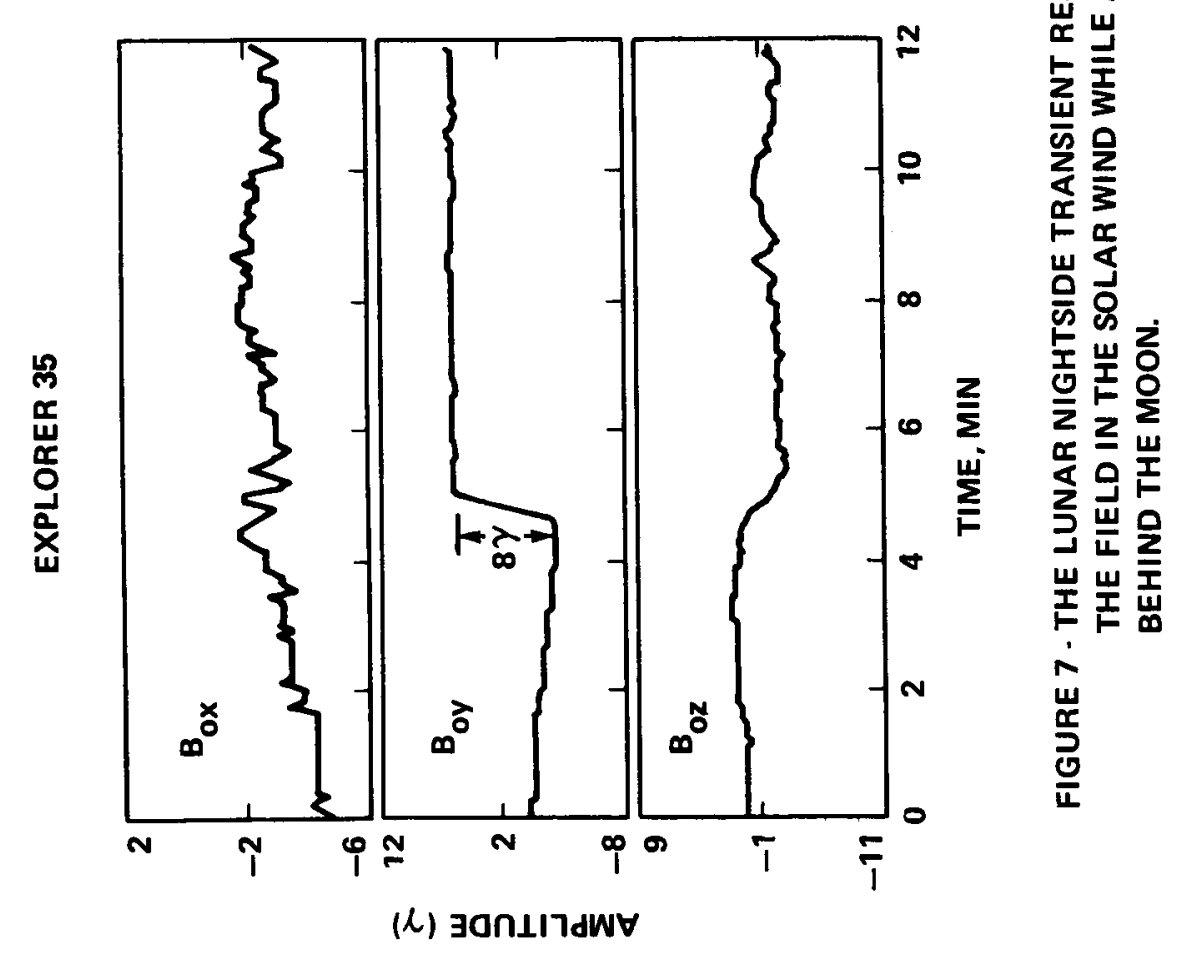




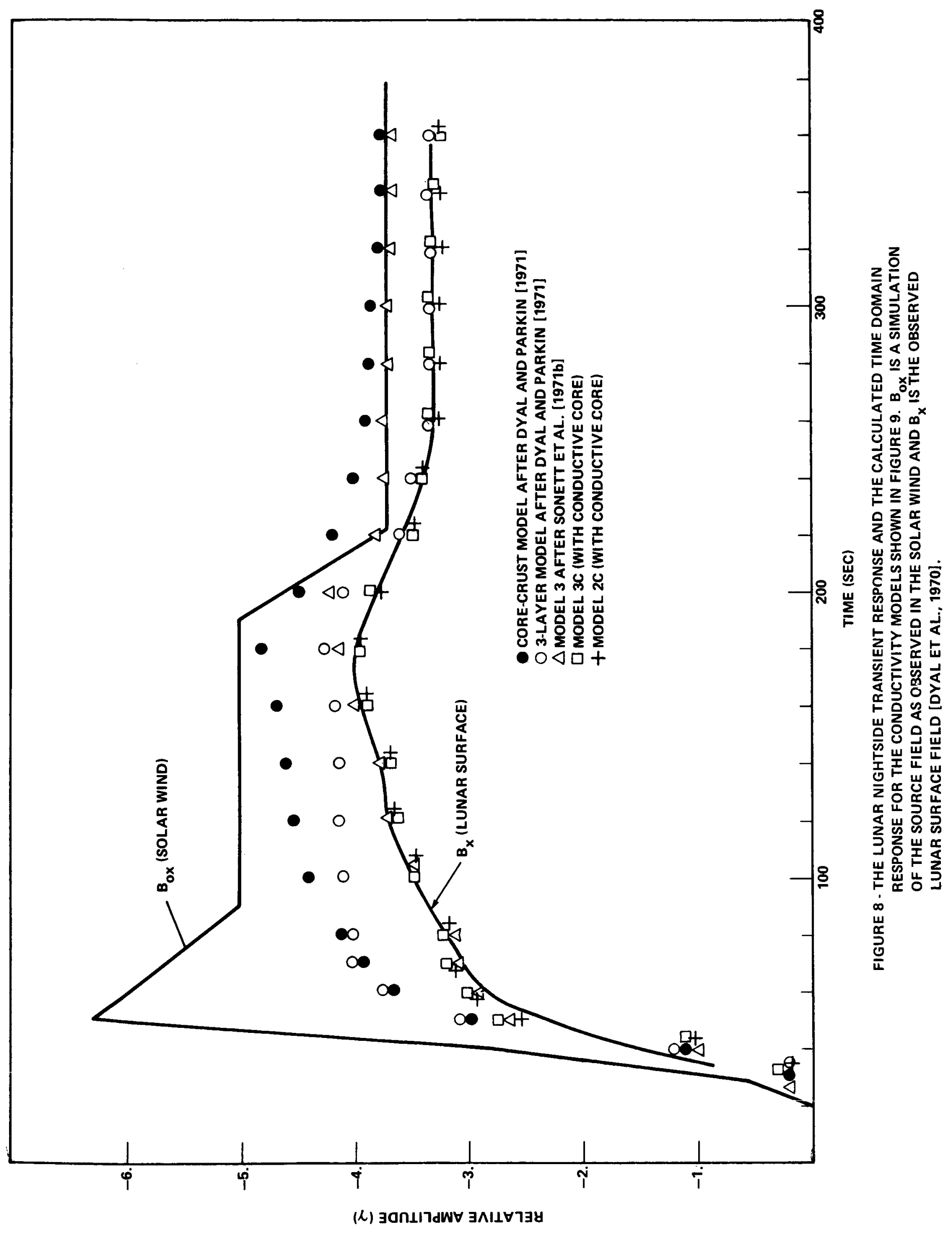




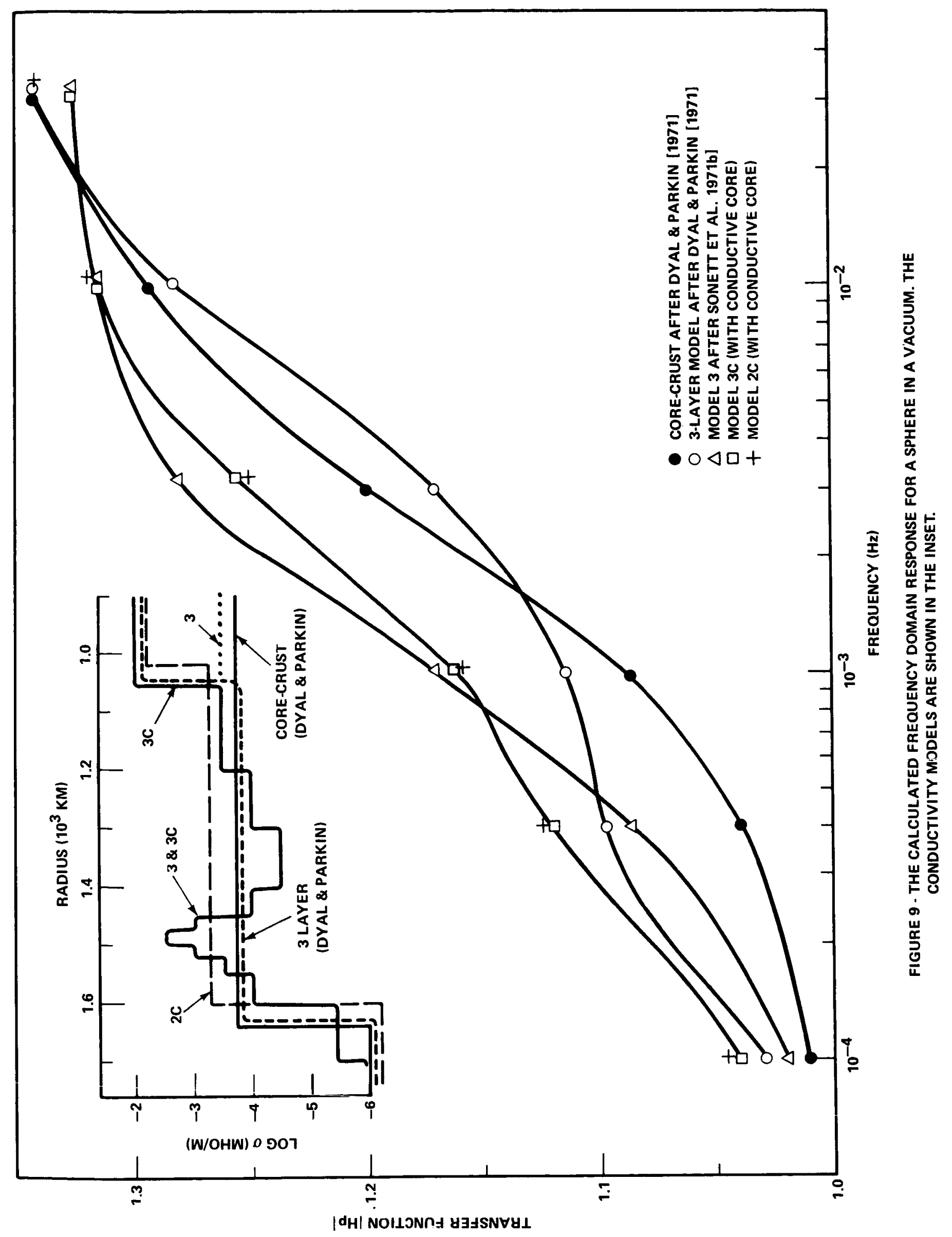




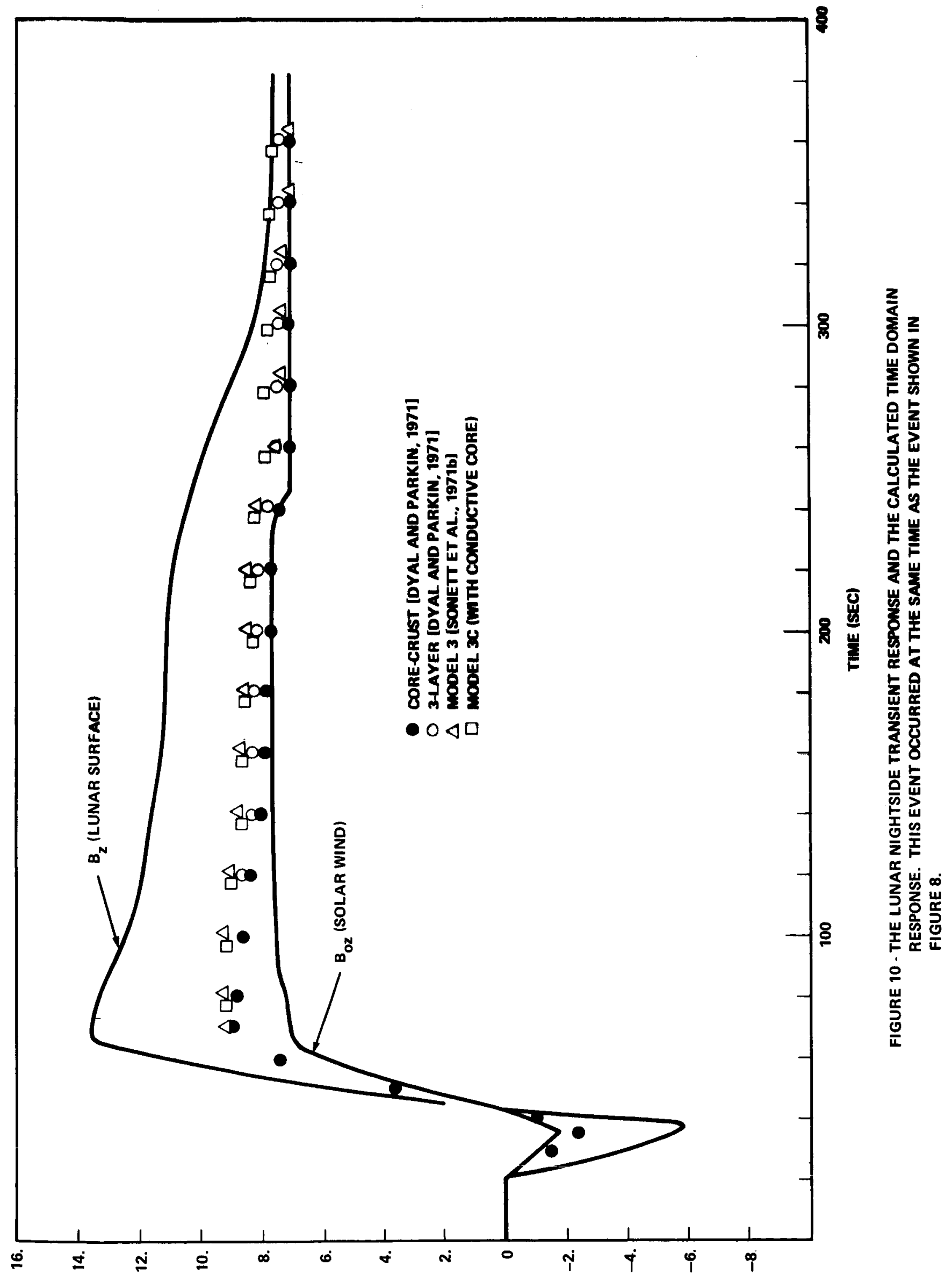

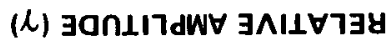




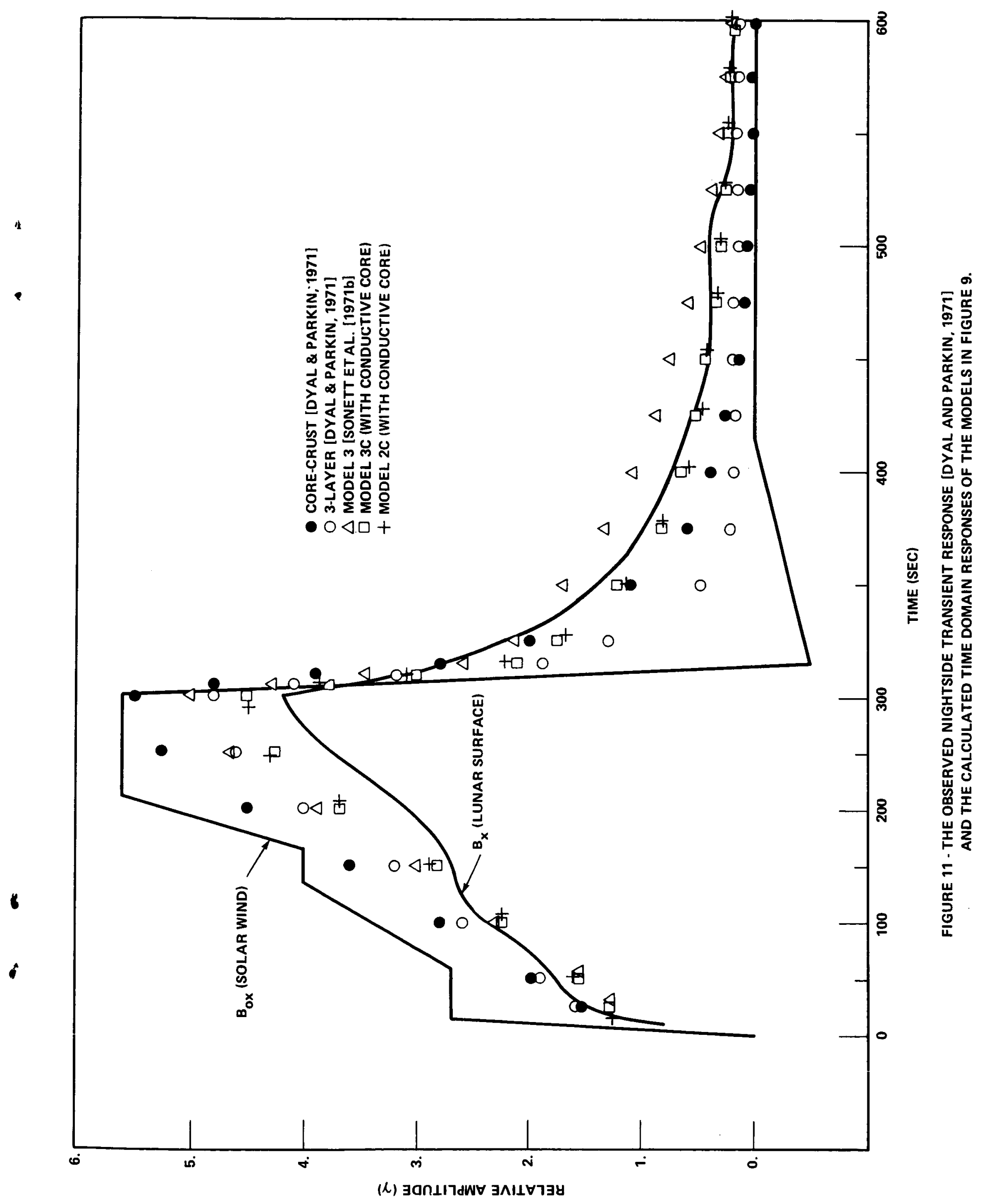

